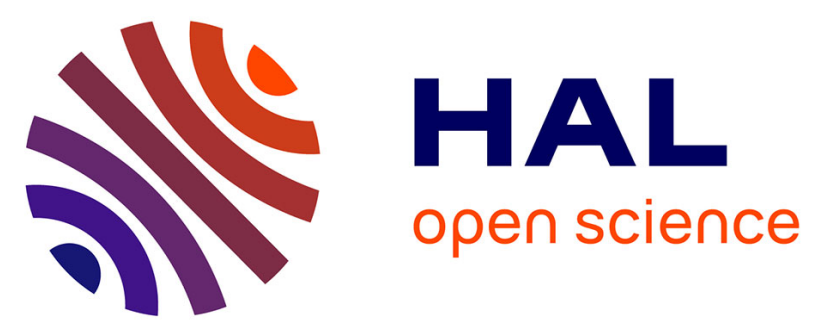

\title{
Photoexcitation of europium(III) in various electrolytes: Dependence of the luminescence lifetime on the type of salts and the ionic strength
}

Annick Nehlig, Mourad Elhabiri, Isabelle Billard, Anne-Marie Albrecht-Gary, Klaus Lützenkirchen

\section{To cite this version:}

Annick Nehlig, Mourad Elhabiri, Isabelle Billard, Anne-Marie Albrecht-Gary, Klaus Lützenkirchen. Photoexcitation of europium(III) in various electrolytes: Dependence of the luminescence lifetime on the type of salts and the ionic strength. Radiochimica Acta, 2003, 91, pp.37-43. hal-02271964

\section{HAL Id: hal-02271964 \\ https://hal.science/hal-02271964}

Submitted on 27 Aug 2019

HAL is a multi-disciplinary open access archive for the deposit and dissemination of scientific research documents, whether they are published or not. The documents may come from teaching and research institutions in France or abroad, or from public or private research centers.
L'archive ouverte pluridisciplinaire HAL, est destinée au dépôt et à la diffusion de documents scientifiques de niveau recherche, publiés ou non, émanant des établissements d'enseignement et de recherche français ou étrangers, des laboratoires publics ou privés. 


\title{
Photoexcitation of europium(III) in various electrolytes: Dependence of the luminescence lifetime on the type of salts and the ionic strength
}

\author{
By Annick Nehlig ${ }^{1}$, Mourad Elhabiri ${ }^{2}$, Isabelle Billard ${ }^{1, *}$, Anne-Marie Albrecht-Gary ${ }^{2, *}$ and Klaus Lützenkirchen ${ }^{1}$ \\ 1 Institut de Recherches Subatomiques, CNRS/IN2P3, Université Louis Pasteur, 23 rue du Loess, F-67037 Strasbourg Cedex 2, France \\ 2 Laboratoire de Physico-Chimie Bioinorganique, UMR 7509 CNRS, ECPM, Université Louis Pasteur, 25, rue Béquerel, \\ F-67000 Strasbourg, France
}

(Received June 18, 2001; accepted in final form May 24, 2002)

\section{Europium / Luminescence / Electrolyte / Complexation}

Summary. The fluorescence characteristics (lifetime, excitation and emission spectra) of aqueous solutions of $\mathrm{Eu}$ (III) containing various supporting electrolytes such as $\mathrm{HCl}, \mathrm{NaCl}$, $\mathrm{LiCl}, \mathrm{CsCl}, \mathrm{MgCl}_{2}, \mathrm{HClO}_{4}$ and $\mathrm{NaClO}_{4}$ have been measured. The observed lifetime variations cannot be properly described neither through the hydration sphere phenomenological approach nor through a Stern-Volmer relationship. Long-range interactions between the excited ion and solvent molecules, in addition to an outer-sphere complexation with the anions, are proposed to account for the observed variations.

\section{Introduction}

The luminescence lifetime of excited lanthanide ions and complexes ranges from microseconds (e.g. $\mathrm{Yb}, \mathrm{Nd})$ to milliseconds (e.g. $\mathrm{Eu}$ and $\mathrm{Tb}$ ). Such a relatively long-lived emission is an attractive feature from an analytical viewpoint, as it allows the implementation of time-gating procedures so that the lanthanide luminescence is readily distinguished from the shorter-lived (sub-microseconds) background present in most of the biological and analytical systems. The two longest lived and most commonly studied emitting lanthanide ions are $\mathrm{Eu}(\mathrm{III})$ and $\mathrm{Tb}(\mathrm{III})$, which possess luminescent ${ }^{5} D_{0}$ and ${ }^{5} D_{4}$ excited states with energies around 17200 and $20500 \mathrm{~cm}^{-1}$, respectively [1]. As the luminescent properties of $\mathrm{Eu}(\mathrm{III})$ cations in solution are sensitive, among other parameters, to the first coordination sphere (containing up to 8 or 9 water molecules) [2], luminescence techniques have become important tools for studying the chemistry of $\mathrm{Eu}(\mathrm{III})$ ions [1-9].

Among the various ligands of interest, the identification of chloride complexes of trivalent actinides $\left(\mathrm{An}^{3+}\right)$ and lanthanides $\left(\mathrm{Ln}^{3+}\right)$ has been the subject of numerous investigations [10-15] because of their importance in actinide separations and in processing chemistry. The nature of the complexes, however, could often not be identified because non-

\footnotetext{
*Authors for correspondence

(E-mail: amalbre@chimie.u-strasbg.fr and/or

isabelle.billard@ires.in2p3.fr).
}

spectroscopic methods such as ion exchange and solvent extraction are unable to distinguish between inner-sphere and outer-sphere (solvent-separated ion pair) complexation.

Apart from the complexation with inorganic ligands, lanthanide ions are also known to form aquo-complexes in solution. Hydration numbers of lanthanide aquo-ions have been repeatedly determined with Time-Resolved Laser-induced Fluorescence Spectroscopy (TRLFS). An empirical linear correlation was employed which relates the reciprocal of the excited-state lifetime (i.e. the decay constant, $k_{\text {obs }}$ ) with the number of water molecules in the first coordination sphere, $N_{\mathrm{H}_{2} \mathrm{O}}$ [1]. In the case of strong ligands that form inner-sphere complexes (especially organic ones), it has been shown that this correlation is not readily applicable [16, 17]. However, the relation might be still reliable in the case of weak ligands, possibly forming only outer-sphere complexes, such as perchlorate or choride salts.

To gain a better understanding of the influence of anions and cations on the luminescence, and on the links between coordination (inner or outer) and the hydration sphere number, we measured lifetimes as well as excitation and emission spectra of aqueous solutions of $\mathrm{Eu}(\mathrm{III})$ containing various supporting electrolytes such as $\mathrm{HCl}, \mathrm{NaCl}, \mathrm{LiCl}$, $\mathrm{CsCl}, \mathrm{MgCl}_{2}, \mathrm{HClO}_{4}$ and $\mathrm{NaClO}_{4}$.

\section{Experimental section}

\section{Chemicals and reagents}

$\mathrm{EuCl}_{3} \cdot 6 \mathrm{H}_{2} \mathrm{O}(99.99 \%)$ and $\mathrm{Eu}_{2} \mathrm{O}_{3}(99.99 \%)$ were obtained from Aldrich and Alfa Aesar, respectively. $\mathrm{NaCl}$ (optical grade, 99.99\%), $\mathrm{LiCl}$ (99.99\%), $\mathrm{CsCl}$ (99.99\%), $\mathrm{MgCl}_{2}$ (99.99\%), $\mathrm{HClO}_{4}(70 \%$ in water, double distilled) were purchased from Aldrich. $\mathrm{Eu}\left(\mathrm{ClO}_{4}\right)_{3} \cdot n \mathrm{H}_{2} \mathrm{O}$ was prepared by dissolving $\mathrm{Eu}_{2} \mathrm{O}_{3}$ into a slightly less than stoichiometric amount of perchloric acid. The mixture was heated for 48 hours at $70{ }^{\circ} \mathrm{C}$ until the $\mathrm{pH}$ became weakly acidic. The solution was slowly evaporated in vacuum and the resulting hydrated europium perchlorate was used without further purification [2]. CAUTION: perchlorate salts combined with organic ligands are potentially explosive and should be handled in small quantity and with the necessary pre- 
cautions [18]. The europium(III) stock solutions were prepared immediately before use from freshly boiled bidistilled water saturated with argon. An aliquot of the stock solution was acidified under $\mathrm{pH}=4$ by addition of sulfuric acid (Carlo Erba 96\%) in order to avoid hydroxyde precipitation and then titrated by Titriplex ${ }^{\circledR}$ III (Merck, $0.1 \mathrm{M})$ with an ammonium acetate buffer and xylene orange as an indicator [19]. The derived europium concentration was $4.85 \times 10^{-2} \mathrm{M}$ and was kept constant for all the experiments.

\section{Luminescence measurements}

The concentration of the various electrolytes was varied in a large range, up to the solubility limit of all the salts used in this work. In order to correctly assess the uncertainty of the measurements, for a given type of solution $(e . g . \mathrm{HCl})$, at least two different stock solutions were prepared and used alternatively to prepare the samples to be measured. The derived uncertainties are reported in Table 1.
Metal-centred excitation and emission spectra were recorded on a Perkin-Elmer LS-50B spectrophotometer fitted with a HAAKE-FJ thermostat, which insured a fixed temperature of $25 \pm 0.2^{\circ} \mathrm{C}$. The source was a pulsed xenon flash lamp with a pulsewidth at half peak height $<10 \mu \mathrm{s}$ and a power equivalent to $20 \mathrm{~kW}$. Flashes were produced with a $20 \mathrm{~ms}$ cycle time. The excitation wavelength was $(394 \pm 1) \mathrm{nm}$, overlapping with the $\mathrm{Eu}(\mathrm{III}){ }^{7} F_{0} \rightarrow$ ${ }^{5} L_{6}$ transition. The emission from the lowest luminescent level to the ground state manifold (i.e., ${ }^{5} D_{0} \rightarrow{ }^{7} F_{1}$ $(592 \mathrm{~nm})$ ) for $\mathrm{Eu}(\mathrm{III})$ was used to obtain the luminescence lifetime. The luminescence decay observed versus time was best fitted with a mono-exponential function. The corresponding lifetimes were determined by averaging at least 3 independent measurements of the same sample.

The delayed fluorescence spectrophotometric data were processed by the SPECFIT software, which uses a global analysis system with expanded factor analysis and Marquardt least-squares minimisation [20-22] and leads to the asso-
Table 1. Effect of addition of electrolyte on the luminescence lifetime of Eu(III) in aqueous solutions of $\mathrm{Eu}\left(\mathrm{ClO}_{4}\right)_{3}$ and $\mathrm{EuCl}_{3} . T=25 \pm 0.2^{\circ} \mathrm{C}$.

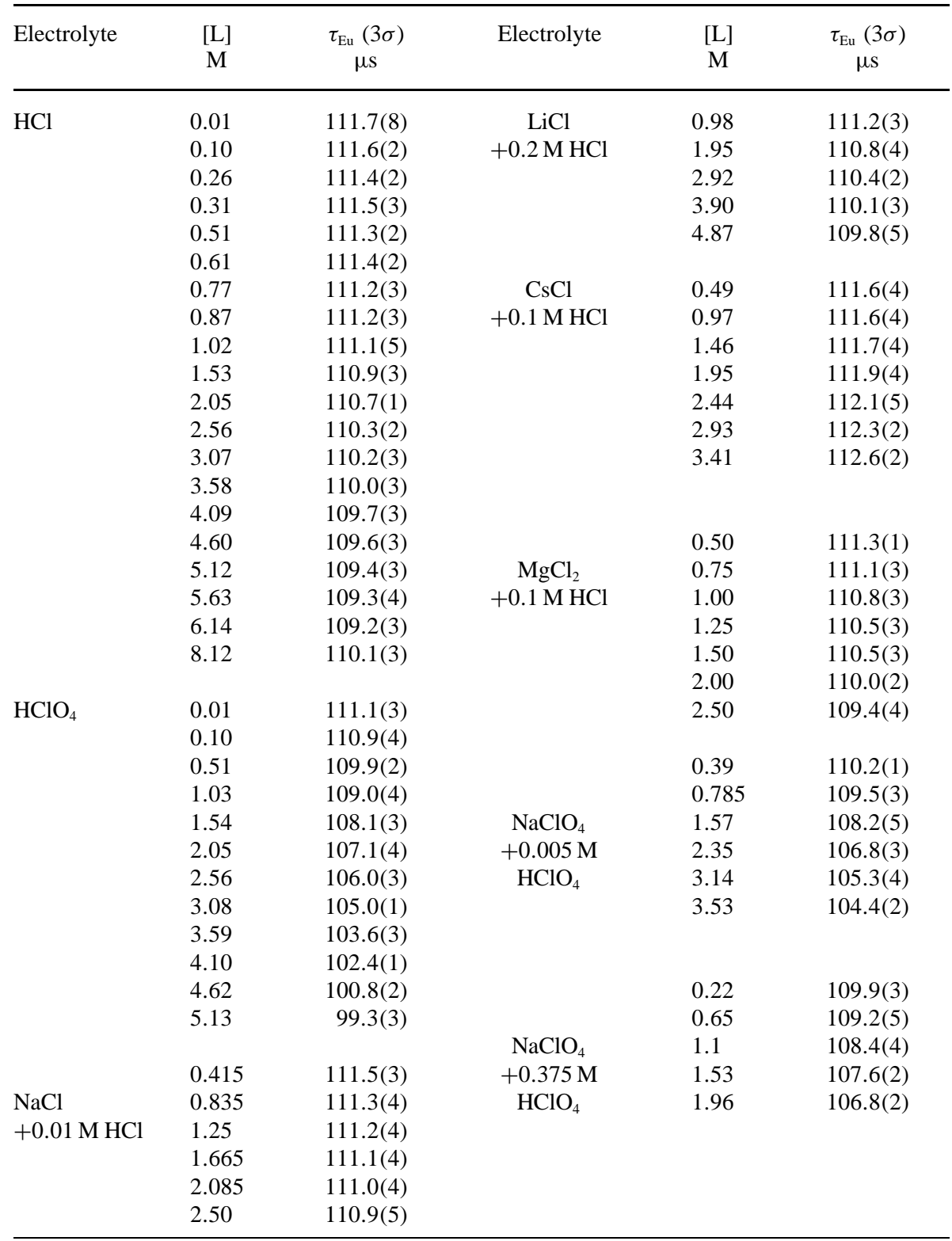


ciation constants of the various species as well as to the corresponding emission spectra.

\section{Results}

The experimental results comprise excitation and emission spectra, together with lifetime determinations. They are discussed separately for the effects of anions and cations.

\section{Effects of anions $\left(\mathrm{Cl}^{-}, \mathrm{ClO}_{4}^{-}\right)$}

Figs. 1 and 2 display the excitation spectra for various $\mathrm{HCl}$ and $\mathrm{HClO}_{4}$ concentrations, respectively, obtained by recording the $\mathrm{Eu}(\mathrm{III})$ emission at $(615 \pm 1) \mathrm{nm}$. Figs. 3 and 4 present the corresponding emission spectra (from excitation at $(394 \pm 1) \mathrm{nm})$. Fig. 5 shows the variation of the $\mathrm{Eu}(\mathrm{III})$ lifetime for a concentration of $\mathrm{HCl}$ from $10^{-2} \mathrm{M}$ to $8 \mathrm{M}$ and a concentration of $\mathrm{HClO}_{4}$ from $10^{-2} \mathrm{M}$ to $5 \mathrm{M}$. In both cases, the lifetimes significantly decrease as a function of the ionic strength within the experimental uncertainties $(3 \sigma$, see Table 1).

Both the excitation and emission spectra in $\mathrm{HCl}$ are sensitive to the total amount of acid added (Figs. 1 and 3). The general trend in the emission spectra is an increase of all

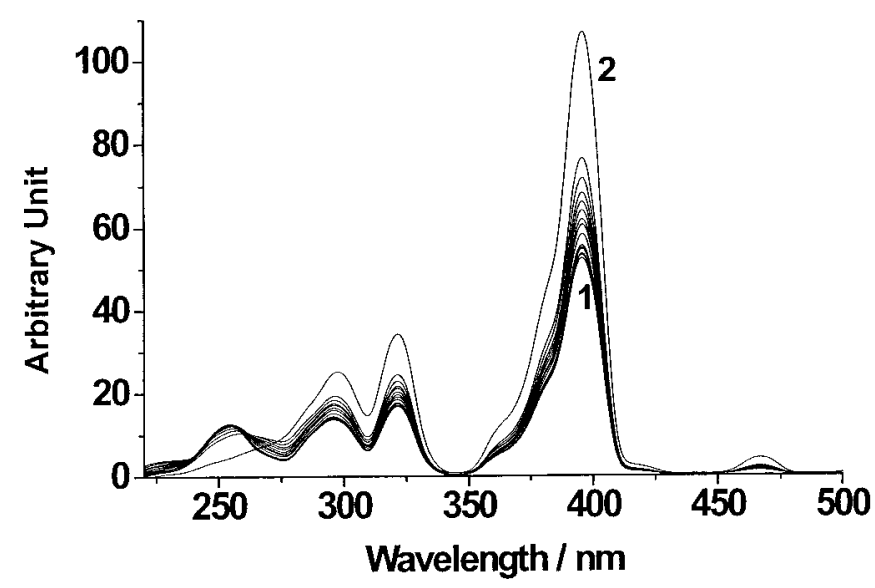

Fig. 1. Excitation spectra (emission at $615 \pm 1 \mathrm{~nm}$ ) of $\mathrm{EuCl}_{3}$ in $\mathrm{HCl}$ solution $10^{-2}-8 \mathrm{M}$. Spectrum $1,[\mathrm{HCl}]=10^{-2} \mathrm{M}$; Spectrum 2, $[\mathrm{HCl}]=$ 8.12 M. $T=25 \pm 0.2^{\circ} \mathrm{C}$.

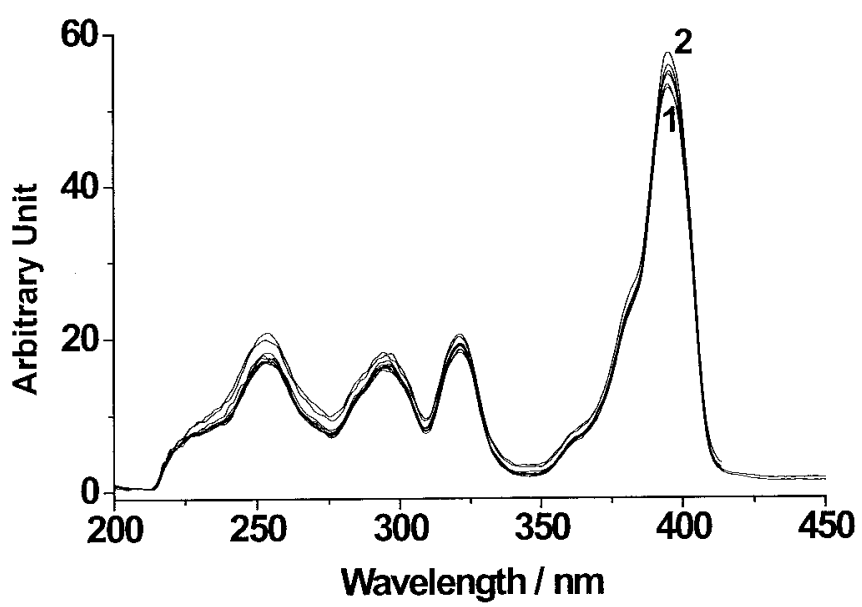

Fig. 2. Excitation spectra (emission at $615 \pm 1 \mathrm{~nm}$ ) of $\mathrm{Eu}\left(\mathrm{ClO}_{4}\right)_{3}$ in $\mathrm{HClO}_{4}$ solution $10^{-2}-5 \mathrm{M}$. Spectrum 1 , $\left[\mathrm{HClO}_{4}\right]=10^{-2} \mathrm{M}$; Spectrum $2,\left[\mathrm{HClO}_{4}\right]=5 \mathrm{M} . \mathrm{T}=25 \pm 0.2^{\circ} \mathrm{C}$. the observed transitions ${ }^{5} D_{i} \rightarrow{ }^{7} F_{j}(i=0,1 ; j=1-2,4)$ as a function of the $\mathrm{HCl}$ concentration. The increase is more pronounced for the hypersensitive ${ }^{5} D_{0} \rightarrow{ }^{7} F_{2}$ transition. In contrast, the excitation and emission spectra for $\mathrm{HClO}_{4}$ are not strongly affected by the addition of large amounts of $\mathrm{HClO}_{4}$. The distortions in the excitation and emission spectra above $6 \mathrm{M} \mathrm{HCl}$ (Figs. 1 and 3) and $4 \mathrm{M} \mathrm{HClO}_{4}$ (Figs. 2 and 4 ) are strong indications of europium precipitation. This

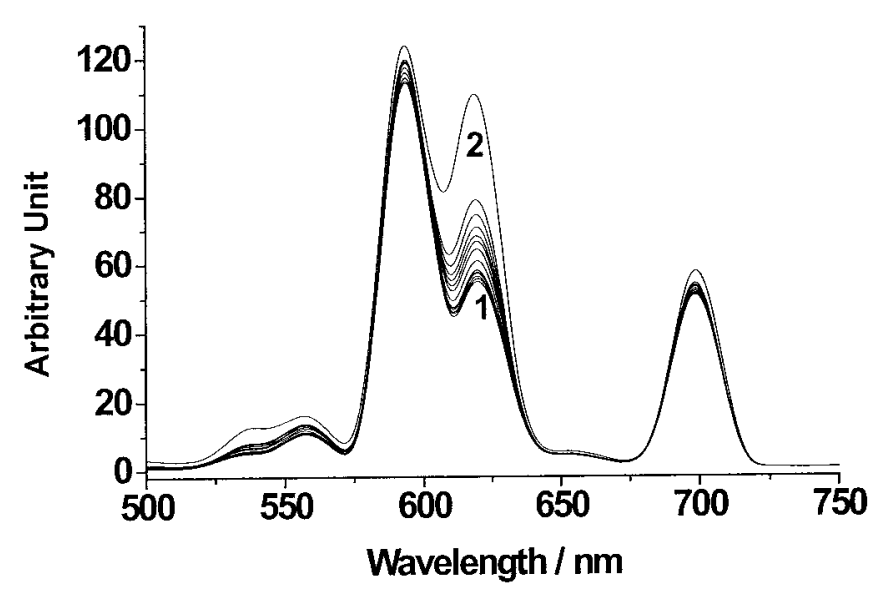

Fig. 3. Emission spectra (excitation at $394 \pm 1 \mathrm{~nm}$ ) of $\mathrm{EuCl}_{3}$ in $\mathrm{HCl}$ solution $10^{-2}-8 \mathrm{M}$. Spectrum $1,[\mathrm{HCl}]=10^{-2} \mathrm{M}$; Spectrum $2,[\mathrm{HCl}]=$ 8 M. $T=25 \pm 0.2^{\circ} \mathrm{C}$.

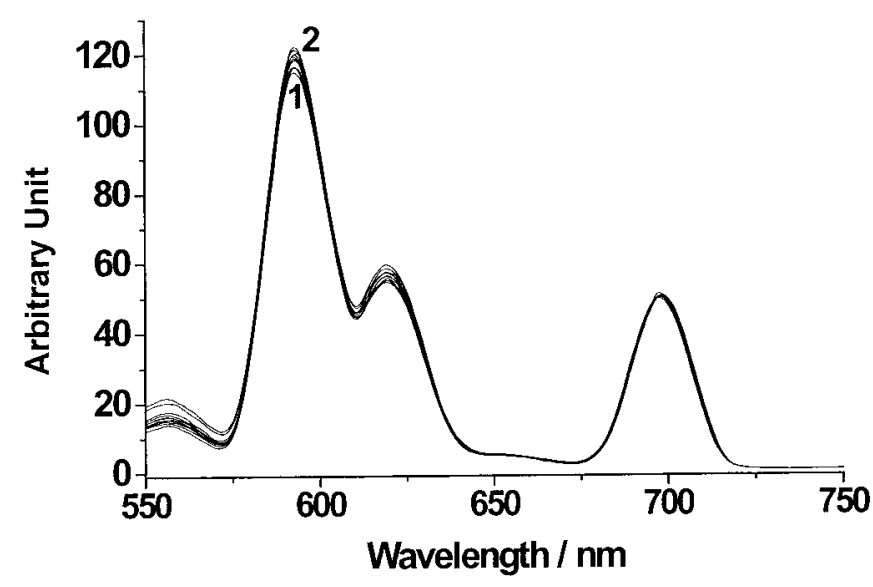

Fig. 4. Emission spectra (excitation at $394 \pm 1 \mathrm{~nm})$ of $\mathrm{Eu}\left(\mathrm{ClO}_{4}\right)_{3}$ in $\mathrm{HClO}_{4}$ solution $10^{-2}-5 \mathrm{M}$. Spectrum 1 , $\left[\mathrm{HClO}_{4}\right]=10^{-2} \mathrm{M}$; Spectrum $2,\left[\mathrm{HClO}_{4}\right]=5 \mathrm{M} . T=25 \pm 0.2^{\circ} \mathrm{C}$.

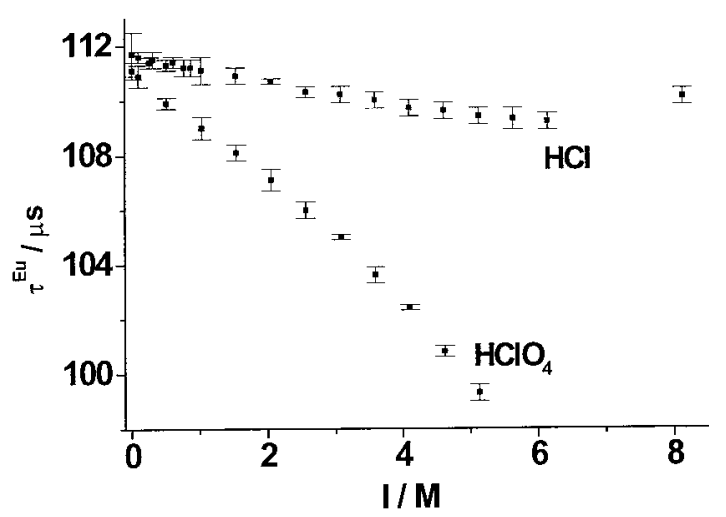

Fig. 5. Plots of the excited ${ }^{5} D_{0}(\mathrm{Eu}(\mathrm{III}))$ lifetime $\tau$ ( $\left.\mu \mathrm{s}\right)$ versus electrolyte concentration $\mathrm{HX}\left(\mathrm{X}=\mathrm{Cl}\right.$ for hydrochloric acid and $=\mathrm{ClO}_{4}$ for perchloric acid). $T=25 \pm 0.2^{\circ} \mathrm{C}$. 
is in line with the increase in lifetime (see Fig. 5, above $6 \mathrm{M}$ $\mathrm{HCl}$ ) and the observed diffusion of laser light in the solution. Hence, these values will not be considered further in the discussion. For the lifetimes as a function of the total amount of acid added, in contrast, the variation is larger in the presence of $\mathrm{ClO}_{4}{ }^{-}$as compared to $\mathrm{Cl}^{-}$(see Fig. 5). The lifetime of the ${ }^{5} D_{0}(\mathrm{Eu}(\mathrm{III}))$ excited state ranges from $111.7 \mu \mathrm{s}$ for $\mathrm{HCl}(0.01 \mathrm{M})$ to $109.2 \mu \mathrm{s}$ for $\mathrm{HCl}(6.14 \mathrm{M})$ (Table 1). The lifetime of the ${ }^{5} D_{0}(\mathrm{Eu}(\mathrm{III}))$ excited state ranges from $111.1 \mu \mathrm{s}$ for $\mathrm{HClO}_{4}(0.01 \mathrm{M})$ to $99.3 \mu \mathrm{s}$ for $\mathrm{HClO}_{4}(5.13 \mathrm{M})$. The lifetime variations are in good agreement with previous determinations done by Barthelemy and Choppin [6].

From these results, it can be seen that addition of increasing amounts of different anions $\left(\mathrm{Cl}^{-}\right.$or $\left.\mathrm{ClO}_{4}^{-}\right)$has a noticeable and specific impact onto $\mathrm{Eu}(\mathrm{III})$ excitation and emission spectra and lifetimes.

\section{Effects of cations $\left(\mathrm{H}^{+}, \mathrm{Li}^{+}, \mathrm{Na}^{+}, \mathrm{Cs}^{+}, \mathrm{Mg}^{2+}\right)$}

To gain more information on cation-dependent interactions, different monovalent and divalent cations associated with chloride or perchlorate counter-anions were studied at a fixed $\mathrm{pH}$ value.

For two values of the $\mathrm{HClO}_{4}$ concentration $\left(\left[\mathrm{HClO}_{4}\right]=\right.$ $5 \times 10^{-3} \mathrm{M}$ and $\left[\mathrm{HClO}_{4}\right]=0.375 \mathrm{M}$, respectively), increasing amounts of $\mathrm{NaClO}_{4}$ have been added to the solutions. For a fixed value of the $\mathrm{HCl}$ concentration (see Table 1) increasing amounts of $\mathrm{LiCl}, \mathrm{NaCl}, \mathrm{CsCl}$ and $\mathrm{MgCl}_{2}$ have been added. An increase of all the $\mathrm{Eu}(\mathrm{III})$ emissions is observed when the concentration of chloride increases (spectra not shown). The lifetime values are given in Table 1. Within the uncertainties (reported in Table 1), the lifetimes vary smoothly as a function of the ionic strength.

Figs. 6 (perchlorate media) and 7 (chloride media) show the lifetime variations as a function of the ionic strength, which is mainly governed by the concentration of the added salt $\left(\mathrm{MgCl}_{2}\right.$, for example) but also depends on the concentration of the acid. Note that the constant contribution to the ionic strength due to the europium salt (equal to $0.291 \mathrm{M}$ ) has not been taken into account in the figures (Figs. 5-7). Therefore, in Fig. 5, the total ionic strength considered is strictly equal to the acid concentration.

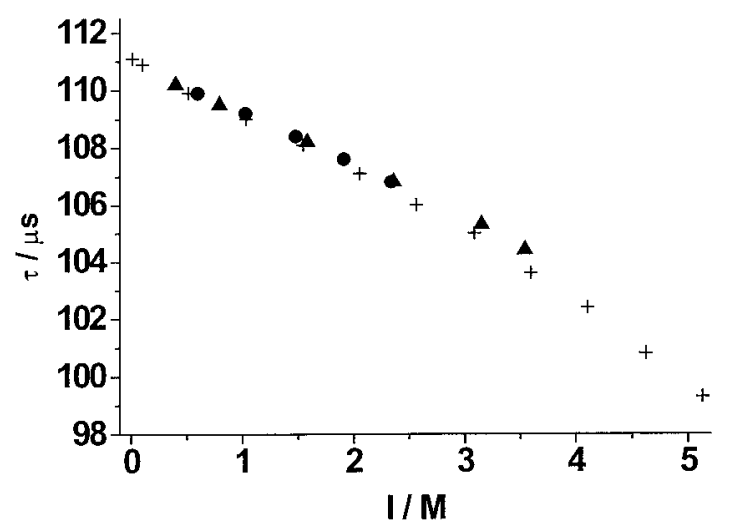

Fig. 6. Plots of the excited state ${ }^{5} D_{0}(\mathrm{Eu}(\mathrm{III}))$ lifetime $\tau$ ( $\left.\mu \mathrm{s}\right)$ versus ionic strength: $(+) \mathrm{HClO}_{4}$ alone $(\boldsymbol{\Delta})$ various amounts of $\mathrm{NaClO}_{4}$, together with $\left[\mathrm{HClO}_{4}\right]=0.005 \mathrm{M}(\mathbf{\bullet})$ various amounts of $\mathrm{NaClO}_{4}$, together with $\left[\mathrm{HClO}_{4}\right]=0.375 \mathrm{M} . T=25 \pm 0.2^{\circ} \mathrm{C}$.

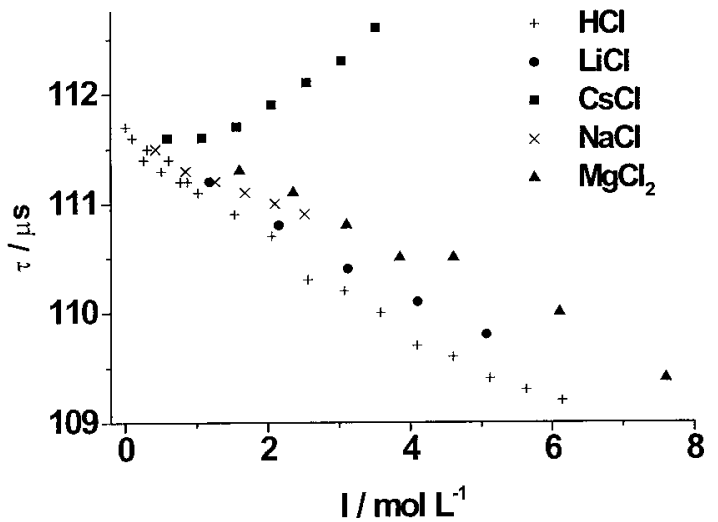

Fig. 7. Plots of the excited state ${ }^{5} D_{0}(\mathrm{Eu}(\mathrm{III}))$ lifetime $\tau$ ( $\left.\mu \mathrm{s}\right)$ for various electrolytes in chloride media. $T=25 \pm 0.2{ }^{\circ} \mathrm{C}$.

The results displayed in Fig. 6 show that in the presence of perchlorate ions, $\mathrm{H}^{+}$and $\mathrm{Na}^{+}$have almost the same effect on the lifetime whatever the ionic strength. In contrast, in chloride media, the replacement of $\mathrm{H}^{+}$by $\mathrm{Na}^{+}$leads to slight changes in the observed lifetime, which appear to be more pronounced at high ionic strength (see Fig. 7). Finally, the replacement of $\mathrm{H}^{+}$by other cations $\left(\mathrm{Mg}^{2+}, \mathrm{Li}^{+}\right.$or $\left.\mathrm{Cs}^{+}\right)$ significantly affects the lifetime (Fig. 7). An increase of the concentrations of $\mathrm{Li}^{+}$and $\mathrm{Mg}^{2+}$ induces a decrease of the corresponding lifetimes, while $\mathrm{Cs}^{+}$leads to an increase.

The ability of cations to decrease the observed lifetimes in chloride media diminishes in the following order:

$$
\mathrm{H}^{+} \approx \mathrm{Li}^{+}>\mathrm{Na}^{+} \approx \mathrm{Mg}^{2+} \gg \mathrm{Cs}^{+} .
$$

In summary, the observed lifetime is approximately constant at $\approx 111.5 \mu$ s for all the salts at low ionic strength. At higher values, however, the measured lifetimes significantly depend on the nature and total concentration of the added salt. Similar salt effects on lifetimes have been reported for other fluorescent lanthanides [23] and also for $\mathrm{UO}_{2}{ }^{2+}[24,25]$. It thus appears to be a general phenomenon.

\section{Discussion}

Actually, an important question of (ground state) coordination chemistry of lanthanides is whether a metal-ligand complex involves inner- or outer-sphere interaction. Complexation reactions are assumed to follow the Eigen-Wilkins mechanism, involving an initial diffusion-controlled formation of an outer-sphere intermediate [26-28]. A second ratelimiting step corresponds to the desolvation of the cation and leads to the inner-sphere complex:

Outer-sphere complexation:

$$
[\mathrm{Ln}(\mathrm{S})]^{3+}+[\mathrm{L}(\mathrm{s})]^{-} \rightleftarrows[\operatorname{Ln}(\mathrm{S}) \mathrm{L}]^{2+}+\mathrm{s} .
$$

Inner-sphere complexation:

$$
[\mathrm{Ln}(\mathrm{S}) \mathrm{L}]^{2+} \rightleftarrows[\mathrm{LnL}]^{2+}+\mathrm{S} .
$$

$\mathrm{S}$ and s are respectively related to the solvation of the lanthanide cation and of the negatively charged ligand.

If the system does not proceed to the second step, complexation results in an outer-sphere complex. To conclude, formation of an inner-sphere complex causes a decrease in 
the number of water molecules coordinated to the $\mathrm{Ln}$ (III) ion while formation of an outer-sphere complex leaves the primary coordination sphere intact.

In the following, before examining possible reasons to explain the observed effects on the lifetimes, it is necessary to gather information obtained by other techniques on these systems. Usually, $\mathrm{Cl}^{-}$and $\mathrm{ClO}_{4}^{-}$, as well as $\mathrm{Br}^{-}, \mathrm{I}^{-}$, $\mathrm{NO}_{3}{ }^{-}$and trichloroacetate counter-anions are considered to only form outer-sphere complexes, even in highly concentrated solutions [29]. Note, however, that EXAFS results on the complexation of lanthanides by chloride anions in aqueous solution seem to indicate an inner-sphere $\mathrm{Cl}^{-}$complexation with $\mathrm{Eu}(\mathrm{III})$ above $3 \mathrm{M} \mathrm{LiCl}$ [11]. In contrast, $\mathrm{F}^{-}$, $\mathrm{OH}^{-}, \mathrm{SO}_{4}{ }^{2-}, \mathrm{IO}_{3}{ }^{-}, \mathrm{CO}_{3}{ }^{2-}$ and acetate lead to a predominantly inner-sphere character [30]. Finally, an "anomalous" increase in the Eu(III) hydration number with increasing concentration of various salts has been reported from excitation spectroscopy [31] and Raman measurements [32,33] (in the last study, particular interest was focussed on $\mathrm{HCl}$, $\mathrm{LiCl}$ and $\mathrm{CsCl}$ ).

Hence, no definite answer has yet been obtained by EXAFS or Raman on how the number of water molecules in the first hydration sphere evolves as a function of the concentration of perchlorate and chloride salt added. Considering the impact of the salt added onto the spectroscopic data (excitation, emission and lifetimes, this work) one can speculate that the present measurements may give some insight into this question.

In the following, we first discuss the various explanations that have been proposed in order to describe the lifetime variations. It appears that none of these is able to describe correctly the whole set of data of this work. A short discussion gives some indications on the possible reasons of this fact. Finally, we propose some route of investigation of all the present fluorescence data, although a comprehensive theoretical treatment of the observed phenomena is out of the scope of this work.

A first approach to describe the observed lifetime variations is given by the Stern-Volmer law. It is based on a deexcitation via two channels, a radiative and a non radiative one, the latter being promoted by the presence of a quencher [34]:

$$
\tau_{0} / \tau=1+K_{\mathrm{SV}}[\mathrm{X}]=1+k_{\mathrm{q}} \tau_{0}[\mathrm{X}] .
$$

The Stern-Volmer constant $K_{\mathrm{SV}}$ is the product of $k_{\mathrm{q}} \times \tau_{0}, k_{\mathrm{q}}$ being the bimolecular rate constant for the dynamic reaction of the quencher with the fluorophore, $\tau_{0}$ is the measured lifetime in the absence of quencher and $[\mathrm{X}]$ is the concentration of the quencher. From Eq. (1), an increase in [X] leads to a decrease in $\tau$.

In chloride media, $K_{\mathrm{Sv}}$ values were calculated by assuming that the lifetime variations are mainly caused by the cations (Table 2). Neglecting the effect of $\mathrm{Cl}^{-}$seems reasonable in a first approach, in view of the small lifetime variations in $\mathrm{HCl}$ as compared to $\mathrm{HClO}_{4}$ (Fig. 5). For $\tau_{0}=111 \mu \mathrm{s}$, the resulting $k_{\mathrm{q}}$ values are at least seven orders of magnitude below the diffusion limit given by the Smoluchowski approach $\left(\approx 10^{10} \mathrm{M}^{-1} \mathrm{~s}^{-1}\right)$. Note that the cation order which can be inferred from the $K_{\mathrm{SV}}$ values does not coincide with that already presented: the rank of $\mathrm{Mg}^{2+}$ in the sequence is very different. This is due to the fact that Eq. (1) depends
Table 2. Stern-Volmer dynamic quenching constants, $K_{\mathrm{SV}}$, and outersphere formation constants, $K_{\text {out }}$, of various electrolytes in aqueous solutions containing europium cation. $T=25 \pm 0.2^{\circ} \mathrm{C}$.

\begin{tabular}{lcc}
\hline Electrolyte & $\log K_{\text {out }}(3 \sigma)$ & $\begin{array}{c}K_{\text {SV }}(3 \sigma) \\
10^{-3} \mathrm{Mol}^{-1} \mathrm{~L}\end{array}$ \\
\hline $\mathrm{HClO}_{4}$ & $-1.9(4)$ & $19(2)$ \\
$\mathrm{NaClO}_{4}$ & $-1.8(2)$ & $18(2)$ \\
$+0.005 \mathrm{M} \mathrm{HClO}_{4}$ & $-1.3(3)$ & $4.0(3)$ \\
$\mathrm{HCl}$ & $-1.4(3)$ & $2.8(7)$ \\
$\mathrm{NaCl}$ & & \\
$+0.01 \mathrm{M} \mathrm{HCl}$ & $-1.3(3)$ & $3.3(4)$ \\
$\mathrm{LiCl}$ & & \\
$+0.2 \mathrm{M} \mathrm{HCl}$ & $-1.7(6)$ & \\
$\mathrm{CsCl}$ & & \\
$+0.1 \mathrm{M} \mathrm{HCl}$ & $-1.3(2)$ & \\
$\mathrm{MgCl}$ & & \\
$+0.1 \mathrm{M} \mathrm{HCl}$ & & \\
\hline
\end{tabular}

a: negative value.

upon the concentration, while Fig. 7 depends upon the ionic strength, for which the +2 charge of $\mathrm{Mg}^{2+}$ is very important.

In perchlorate media, given the very small influence of the cations (Fig. 6) a $K_{\text {SV }}$ value can be obtained by considering only the effect of $\mathrm{ClO}_{4}{ }^{-}$concentration (Table 2).

However, we would like to discuss several arguments that indicate the inadequacy of Eq. (1) to describe the results of the present work:

i) In the case of $\mathrm{CsCl}$, it is clear that the experimental variations will lead to a negative value of $K_{\mathrm{Sv}}$, which is not physically reasonable, although some publications have presented negative $K_{\mathrm{Sv}}$ values [35].

ii) The Stern-Volmer constant $K_{\mathrm{Sv}}$ depends on the ionic strength $[36,37]$. Considering the high salt concentrations used, deviations from linearity in the plot $\tau_{0} / \tau$ versus $[\mathrm{X}]$ could therefore be attributed either to this ionic strength dependence or to an inadequacy of Eq. (1), without any possibility to decide between the two interpretations.

iii) As stressed above, both cations and anions decrease the measured lifetimes. Thus, two Stern-Volmer constants should be introduced for each salt considered, which renders their determination impossible.

Finally, it has to be stressed that the Stern-Volmer equation is a phenomenological approach and is not indicative of any mechanism: it can be successfully applied both for collisional processes or for energy transfers [34]. It is therefore of little use to the question of inner- versus outer-sphere interactions. Furthermore, its formulation does not explicitly take into account the water molecules and is thus not adapted to the question of the hydration number. All these reasons explain why another approach for the description of the lifetime variations is usually preferred.

An alternative interpretation is to ascribe the lifetime variations to changes of the $\mathrm{Eu}(\mathrm{III})$ first hydration sphere, following a procedure commonly used by various authors and first based on the work of Horrocks and co-workers in solid samples [1]. In the first version of this approach, the experimental decay rate of an europium-based fluorescent 
probe measured in $\mathrm{H}_{2} \mathrm{O}, \lambda_{\text {obs }}$, is the the sum of three terms:

$$
\lambda_{\text {obs }}=k_{\text {rad }}+k_{\text {nrad }}+N_{\mathrm{H}_{2} \mathrm{O}} k_{\mathrm{H}_{2} \mathrm{O}},
$$

where $k_{\text {rad }}$ is the intrinsic decay rate, and $k_{\text {nrad }}$ represents all the deactivation pathways other than energy transfers through $\mathrm{OH}$ vibrations. The deactivation processes occuring through $\mathrm{OH}$ vibrations are described in the last term, where $N_{\mathrm{H}_{2} \mathrm{O}}$ is the number of water molecules in the first coordination sphere. $k_{\mathrm{H}_{2} \mathrm{O}}$ is the decay rate due to one water molecule and can be determined by calibration procedures on well-characterised samples [1]. The term $\left(k_{\mathrm{rad}}+k_{\mathrm{nrad}}\right)$ can be experimentally determined by measuring the decay rate of the fluorescent probe in $\mathrm{D}_{2} \mathrm{O}, \lambda_{\mathrm{D}_{2} \mathrm{O}}$, which leads to:

$$
N_{\mathrm{H}_{2} \mathrm{O}}=\left(\lambda_{\text {obs }}-\lambda_{\mathrm{D}_{2} \mathrm{O}}\right) / k_{\mathrm{H}_{2} \mathrm{O}} .
$$

If this method (referred to in the following as the "exact" method) is used to determine $N_{\mathrm{H}_{2} \mathrm{O}}$ as a function of the concentration of a ligand [1], two series of measurements are required, one in $\mathrm{D}_{2} \mathrm{O}$ and one in $\mathrm{H}_{2} \mathrm{O}$. A simplified version of this method is usually applied by assuming that the term $\lambda_{\mathrm{D}_{2} \mathrm{O}}$ is independent of the ligand concentration, which means that the ligand does not contribute to the nonradiative decay of the $\mathrm{Eu}(\mathrm{III})$ excited state. Under this assumption, one has:

$$
N_{\mathrm{H}_{2} \mathrm{O}}=\alpha \times \tau^{-1}-\beta \text {. }
$$

For europium, $\alpha=1.05 \mathrm{~ms}$ and $\beta=0.70$ ("simplified" method).

This method has been extended to the case of electrolytes added to aqueous solutions of europium [38].

In a first step, the question whether the "exact" or the "simplified" version of the method should be applied to our data has to be examined. Experimental lifetime values in $\mathrm{D}_{2} \mathrm{O}$ exist in the literature [38] for some of the salts that have been considered in this work $\left(\mathrm{NaClO}_{4}, \mathrm{NaCl}\right.$ and $\left.\mathrm{HCl}\right)$. We have therefore examined this $\mathrm{D}_{2} \mathrm{O}$ correction term for these three series of solutions. It turns out that the $\tau_{\mathrm{D}_{2} \mathrm{O}}=\lambda_{\mathrm{D}_{2} \mathrm{O}}^{-1}$ values vary from roughly $2.7 \mathrm{~ms}(0.01 \mathrm{M})$ to $4 \mathrm{~ms}$ (above $8 \mathrm{M})$. Thus, although such variations are significant, $\lambda_{\mathrm{D}_{2} \mathrm{O}}$ is rather small as compared to $\lambda_{\mathrm{H}_{2} \mathrm{O}}$ so that the corrected lifetime values are shifted by an almost constant offset which does not affect the general trend of the data. Finally, considering the "simplified" method (Eq. (2bis)), the value of $112 \pm 1 \mu$ s obtained in the present work at low salt concentration corresponds to $8.7 \pm 0.1$ water molecules, in good agreement with values obtained by other techniques $[39,40]$. This had to be expected since a value of $110 \mu$ s and a hydration number of 8.5 are used to calibrate Eq. (2bis) [38].

Whatever the method used (exact or simplified), the data in Figs. 5-7 (except $\mathrm{CsCl}$ ) yield an increase of the hydration number as a function of the salt concentration (see Eq. (2bis)) which appears surprising. As a qualitative explanation of such a behaviour, Lis and Choppin suggested an essentially constant primary hydration number with increasing quenching as a function of salt concentration. The increase would be due to stronger interactions of the $\mathrm{Eu}(\mathrm{III})$ ion with the $\mathrm{OH}$ oscillators already present in the inner coordination sphere [38]. This stronger metal-water interaction in the primary sphere would result from a diminution of the secondary hydration sphere caused by the increasing concentration of ions.

This interpretation, however, appears problematic for two reasons:

i) it is not in line with the physical concept of Eq. (2) which is based on a quenching contribution of each of the $\mathrm{O}-\mathrm{H}$ oscillators independent of all others and limited to the first hydration sphere.

ii) The interpretation should be consistent with experimental results on the solvation and water structure in concentrated solutions of the various salts. For example, in $\mathrm{KCl}$ and $\mathrm{NaCl}$ concentrated aqueous solutions the number of water molecules associated to an ion pair is $5.0 \pm 0.4$. For $\mathrm{CsCl}$, however, the number of water molecules associated to an ion pair is $2.8 \pm 0.4$ [41]. The respective value should be equal to $\sim 6$ for $\mathrm{LiCl}$ concentrated solutions, one water molecule being shared between two $\mathrm{Cl}^{-}$ions [42]. From these experimental results and according to refs. $[1,38]$, the fluorescence lifetime should vary in the same way for all salts, with a less pronounced variation for $\mathrm{CsCl}$ as compared to $\mathrm{NaCl}$ and $\mathrm{KCl}$. Therefore, it is difficult to understand why a smaller number of water association would lead to an opposite trend between $\mathrm{NaCl}$ and $\mathrm{CsCl}$ for the lifetime variations. Thus, the determination of the first hydration sphere through the use of Eq. (2) for data of the present type appears doubtful.

In fact, the description of the lifetime variations through Eqs. (1) or (2) seems unrealistic. The problem is obviously multiparametric in nature: by addition of salts, many physico-chemical properties of the system are modified, such as viscosity, density, dielectric constant, refractive index, conductivity, ion mobility, etc. Most likely a plot of any of these parameters as a function of the ionic strength will lead to smooth variations, similar to those found for the lifetime variations. None of these parameters can be considered as a "good" parameter in the sense that it might provide a real physical correlation.

We thus propose that the lifetime values should be regarded together with the emission and excitation spectra, in order to gain insight into the behaviour of ions in solution.

Qualitatively speaking, the significant changes observed in the measured excitation and emission spectra in chloride media (Figs. 1, 3) are tentatively ascribed to an outersphere complexation process. This is in line with some of the experimental results discussed above for the chloride media [29]. On a quantitative basis, assuming that the fluorescence process is determined by outer-sphere complexation, equilibrium constants $K_{\text {out }}$ were derived from the emission spectra (also for $\mathrm{ClO}_{4}{ }^{-}$) and are summarised in Table 2. Note that the derived values are not thermodynamic ones, due to large changes in the total ionic strength of the solutions. The rather small values obtained for the chloride media are in good agreement with those published previously for slightly different temperature and ionic strengths [31]. It can be seen from Table 2 that the cation does not strongly influence $K_{\text {out }}$ in chloride media. Several methods for estimating $K_{\text {out }}$ are known, based on theoretical expressions, such as the Fuoss approach [43]. In the case of an interaction between a $(+3)$ 
charge and a $(-1)$ charge, the theory leads to larger $K_{\text {out }}$ values than those obtained in this work, which rules out the possibility of inner-sphere complexation.

The $K_{\text {out }}$ values for $\mathrm{Cl}^{-}$and $\mathrm{ClO}_{4}{ }^{-}$differ slightly but are nevertheless of the same order of magnitude, which would pledge for the above assumption of an outer-sphere complexation process in perchlorate media as well, and would be also sustained by the small changes in the excitation and emission spectra (see Figs. 2 and 4).

Regarding lifetime variations, it seems that outer-sphere complexation is not the main cause. In particular, the lifetime variation appears more sensitive to perchlorate ions as compared to chloride ions, and are sensitive to the nature of the cations. The measured luminescence lifetime and its variation reflect a non-radiative deexcitation mechanism. It is most probably based on the vibrational energy transfers to high-energy vibrations of solvent molecules of the bulk. Note that in $\mathrm{D}_{2} \mathrm{O}$, the $\tau^{-1}$ variations as a function of the added salt concentration are not flat [38]: even in $\mathrm{D}_{2} \mathrm{O}$, adding electrolytes has an impact on the measured lifetimes (or decay rates), which obviously cannot be related to the presence of $\mathrm{OH}$ bounds. This implies that ionic interactions play a role, and that the nature of the solvent has to be considered as well. From the present experimental results, it is clear that both anions (Fig. 5) and cations (Fig. 7) have an impact onto the measured lifetimes. In this sense, lifetime measurements provide global information on various interactions occurring in the solution, both on long and short distances [44].

In order to further improve the understanding of the phenomenon a theoretical study seems necessary. It could be based on the Förster formalism [45] but is out of the scope of this work.

\section{Conclusion}

Luminescence excitation spectroscopy of the ${ }^{7} F_{0} \rightarrow{ }^{5} D_{0}$ transition in $\mathrm{Eu}(\mathrm{III})$ is valuable for the characterisation of the $\mathrm{Eu}(\mathrm{III})$ environment. Our study reveals that luminescence lifetime measurements in aqueous solutions cannot be properly described neither by the hydration sphere phenomenological approach nor by a Stern-Volmer relationship. The complex trend observed for the Eu(III) lifetime as a function of the concentration of various anions and cations is likely due to long-range interactions between the excited ion and vibrational degrees of freedom of solvent molecules, in addition to an outer-sphere complexation with the anions, which affects excitation and emission spectra.

Our experimental results highlight the complexity of the various phenomena, especially the solvent effects, which govern the overall lifetime values. Additional experimental as well as theoretical work is needed which should go beyond the simple phenomenological approach examined in this work to describe long-range interactions.

Acknowledgment. This work has been supported by the Centre National de la Recherche Scientifique (CNRS). Elizabeth Nolan is gratefully acknowledged for fruitful discussions and comments on the manuscript.

\section{References}

1. Horrocks, W., Sudnick, D. R.: J. Am. Chem. Soc. 101, 334 (1979).

2. Bünzli, J. C. G., Choppin, G. R.: Lanthanide probes in life, chemical and earth sciences: theory and practise. Elsevier, Amsterdam (1989).

3. Kropp, J. L., Windsor, M. W.: J. Phys. Chem. 71, 477 (1967).

4. Haas, Y., Stein, G.: J. Phys. Chem. 75, 3677 (1971).

5. Haas, Y., Stein, G.: J. Phys. Chem. 75, 3668 (1971).

6. Barthelemy, P. P., Choppin, G. R.: Inorg. Chem. 28, 3354 (1989).

7. Choppin, G. R., Peterman, D. R.: Coord. Chem. Rev. 174, 283 (1998).

8. Parker, D.: Coord. Chem. Rev. 205, 109 (2000).

9. Keefe, M. H., Benkstein, K. D., Hupp, J. T.: Coord. Chem. Rev. 205, 201 (2000).

10. Allen, P. G., Bucher, J. J., Shuh, D. K., Edelstein, N. M., Reich, T.: Inorg. Chem. 36, 4676 (1997).

11. Allen, P., Bucher, J., Shuh, D., Edelstein, N., Craig, I.: Inorg. Chem. 39, 595 (2000).

12. Fanghänel, T., Kim, J. I., Klenze, R., Kato, Y.: J. Alloys Comp. 225, 308 (1995).

13. Fukasawa, T., Kawasuji, I., Mitsugashira, T.: Bull. Chem. Soc. Japan 55, 726 (1982).

14. Johansson, G., Yokoyama, H.: Inorg. Chem. 29, 2460 (1990).

15. Yaita, T., Narita, H., Suzuki, S., Tachimori, S., Motohashi, H., Shiwaku, H.: J. Radioanal. Nucl. Chem. 239, 371 (1999).

16. Beeby, A., Clarkson, I., Dickins, R., Faulkner, S., Parker, D., Royle, L., de Sousa, A., Williams, J., Woods, M.: J. Chem. Soc., Perkin Trans. 2, 493 (1999).

17. Parker, D., Williams, J.: J. Chem. Soc., Dalton Trans. 3613 (1996).

18. Wosley, W. C.: J. Chem. Edu. 50, A335 (1973).

19. Merck, E.: "Méthodes d'analyses complexométriques avec les titriplex $^{\circledR}$ ". 3rd edition (Merck, E., Ed.) Grafis, Darmstadt (1992).

20. Malinowski, E. R.: Factor analysis in chemistry. 2nd edition ed., Wiley Interscience, New-York (1991).

21. Maeder, M., Zuberbühler, A. D.: Anal. Chem. 62, 2220 (1990).

22. Gampp, H., Maeder, M., Meyer, C., Zuberbühler, A. D.: Talanta 33, 943 (1986)

23. Kimura, T., Kato, Y.: J. Alloys Comp. 278, 92 (1998).

24. Bouby, M., Billard, I., Bonnenfant, A., Klein, G.: Chem. Phys. 240, 353 (1999).

25. Rustenholtz, A., Billard, I., Duplâtre, G., Lützenkirchen, K., Sémon, L.: Radiochim. Acta 89, 83 (2001).

26. Eigen, M., Wilkins, R. G.: Adv. Chem. Ser. 49, 55 (1965).

27. Cossy, C., Helm, L., Merbach, A. E.: Inorg. Chem. 27, 1973 (1988).

28. Cossy, C., Merbach, A. E.: Pure Appl. Chem. 60, 1785 (1988).

29. Bünzli, J. C.: In: Rare earths. (Saez Puche, R., Caro, P., eds.) Editorial Complutense, Madrid (1998) p. 223.

30. Martell, A. E., Smith, R. M.: Critical stability constants. Vol.3, Plenum Press, New York (1982).

31. Breen, P. J., Horrocks, W.: Inorg. Chem. 22, 536 (1983).

32. Kanno, H., Hiraishi, J.: J. Phys. Chem. 86, 1488 (1982).

33. Kanno, H., Yokoyama, H.: Polyhedron 15, 1437 (1996).

34. Birks, J.: Photophysics of aromatic molecules. Wiley-Interscience, London (1970).

35. Kessler, M. A.: Anal. Chim. Acta 364, 125 (1998).

36. Verity, B., Bigger, S.: J. Chem. Kin. 28, 919 (1996).

37. Tanaka, F., Ishibashi, T., Okamoto, M.: J. Photochem. Photobiol. A 74, 15 (1993).

38. Lis, S., Choppin, G.: Mat. Chem. Phys. 31, 159 (1992).

39. Habenschuss, A., Spedding, F. H.: J. Chem. Phys. 73, 442 (1980).

40. Yamaguchi, T., Nomura, M., Wakita, H., Ohtaki, H.: J. Chem. Phys. 89, 5153 (1988).

41. Max, J. J., Chapados, C.: J. Chem. Phys. 113, 6803 (2000).

42. Ansell, S., Neilson, G. W.: J. Chem. Phys. 112, 3942 (2000).

43. Wilkins, R. G.: The study of kinetics and mechanism of reactions of transition metal complexes. Allyn and Bacon, Inc., Boston (1974).

44. Billard, I., Rustenholtz, A., Sémon, L., Lützenkirchen, K.: Chem. Phys. 270, 345 (2001).

45. Förster, T.: Dis. Faraday Soc. 27, 7 (1959). 